\title{
ANTIBIOGRAM OF PREVALENT MICROORGANISMS IN WOUND INFECTIONS- A COMPARATIVE STUDY BETWEEN DIABETIC AND NON-DIABETIC PATIENTS ATTENDING A TERTIARY CARE HOSPITAL
}

\author{
Yusra Fatima1, Maimoona Mustafa ${ }^{2}$
}

${ }^{1}$ Resident, Department of Microbiology, Deccan College of Medical Sciences, Kanchanbagh, Hyderabad.

2 Professor and HOD, Department of Microbiology, Deccan College of Medical Sciences, Kanchanbagh, Hyderabad.

\section{ABSTRACT}

\section{BACKGROUND}

Management of wound infections is a challenge even today due to inadequate understanding of microbial pattern and therapeutic approaches. This study was thus designed to identify the isolates to study the antibiograms of these isolates infecting the wounds of diabetic and non-diabetic patients in various departments of a tertiary care unit.

\section{MATERIALS AND METHODS}

280 patients (diabetic and non-diabetic) with infected wounds were included in this study. Wound swabs (from HiMedia) were inoculated on Nutrient Agar, Blood Agar and MacConkey Agar media and incubated. Smears were prepared from the colonies thus obtained, Gram-stained followed by identification and confirmation of isolates as per standard microbiological guidelines. Their antibiotic sensitivity pattern was detected using Kirby-Bauer Disc Diffusion method on Mueller-Hinton Agar Medium as per CLSI guidelines.

\section{RESULTS}

In this study, it was found that gram negative bacterium Escherichia coli was most prevalent pathogenic organism both in diabetic and non-diabetic cases of wound infection. Staphylococcal isolates from non-diabetic patients showed maximum sensitivity towards Cefoperazone, among the Cephalosporins tested. Gram-negative bacteria showed greater sensitivity to Amikacin in nondiabetic and to Imipenem in diabetic patients.

\section{CONCLUSION}

Rate of wound infection was found to be more in diabetic patients when compared to non-diabetic patients. The prevalence of polymicrobial isolates was more in diabetic patients, which could be due to reduced host immune responses in them.

\section{KEYWORDS}

Wound Infection, Burns, Staphylococcus aureus, Escherichia coli, Pseudomonas.

HOW TO CITE THIS ARTICLE: Fatima Y, Mustafa M. Antibiogram of prevalent microorganisms in wound infections- a comparative study between diabetic and non-diabetic patients attending a tertiary care hospital. J. Evolution Med. Dent. Sci. 2017;6(85):59245927, DOI: $10.14260 /$ jemds/2017/1288

\section{BACKGROUND}

A wound is "a breakdown in the protective function of the skin; the loss of continuity of epithelium with or without loss of underlying connective tissue (i.e. muscle, bone, nerves) following injury to the skin or underlying tissues/ organs caused by surgery, a blow, a cut, chemicals, heat/ cold, friction/ shear force, pressure or as a result of disease such as leg ulcers or carcinomas." [1] Ulceration is a wound that constantly exposes the underlying tissue to the environment. Thus, a wound implies a portal for entry of microbes into the body. When organisms which are not generally pathogenic to the tissues colonise a wound, they can cause infection. Open wounds, unhygienic living conditions and co-morbid conditions like diabetes mellitus, malnutrition and obesity are certain aspects that largely contribute to this.[2]

'Financial or Other Competing Interest': Dr. Fatima reports grants from Indian Council of Medical Research, during the conduct of the study.

Submission 27-08-2017, Peer Review 12-10-2017,

Acceptance 18-10-2017, Published 23-10-2017.

Corresponding Author:

Yusra Fatima,

\#16-2-838/A/2, LIC Colony,

Saidabad, Hyderabad-500059.

E-mail:yusrafatima26@gmail.com

DOI: $10.14260 /$ jemds $/ 2017 / 1288$

\section{(c) $($ ) $९$}

"Diabetes mellitus is a heterogeneous group of clinical disorders with abnormalities in the metabolism of carbohydrates, protein and fat that results primarily from the deficiency in the synthesis, secretion or function of insulin. The disease is associated with microvascular, macrovascular and metabolic complications."[3] The microvascular disease due to 'sugar-coated capillaries' limits the blood supply to the superficial and deep structures.[4] Trauma or surgery further compromises the local blood supply at the microvascular level predisposing the patient to infection. The infection may involve the skin, soft tissue, bone or all of these tissues. ${ }^{[4]}$ In addition diabetic patients are at a higher risk of wound infections, which usually follow a severe course depending on their nutritional and glycaemic status.[5] A significant association has been found between the severity of infections and insulin sensitivity in healthy individuals. [6]

Results of previous studies have elucidated antibiotic resistance in microorganisms as an important cause of wound infections. The prevalence and incidence of postoperative wound infection varies between procedures, hospitals, surgeons, patients and geographical location. Although, all patients receive surgical prophylactic antibiotics, infection rate in post-operative wound infections is high. This is probably due to inappropriate antibiotic regime.[7] Proper identification of the cause and appropriate 
drug regime in cases of wound infections is essential in management of complications and achieving a successful outcome.

Unfortunately, management of wound infections remains a challenge due to inadequate understanding of microbial pattern and therapeutic approaches. Hence, this study is designed to probe the antibiograms of microorganisms infecting the wounds of diabetic and non-diabetic patients in various departments of a tertiary care unit.

\section{MATERIALS AND METHODS}

This study has been done in a tertiary care hospital, during June 2014 - Jan 2016. The study was carried out after being approved by the Institutional Ethics Committee.

\section{Study Design}

This is a descriptive study involving 280 cases of wound infection in various departments of a tertiary care unit. The distribution of cases was as follows:

Diabetic Cases- 148.

Non-Diabetic Cases- 132.

With the informed consent of all the enrolled subjects, about 280 wound samples were collected. Pus collection was done by using two sterile swabs (obtained from HiMedia Pvt. Ltd.) and rolling over the wound surface under aseptic precautions. The specimens were transported to the lab immediately and processed using standard microbiological techniques.[8]

One swab was used to make a smear and the other was used for inoculation on Blood Agar and MacConkey Agar media and incubated at $37^{\circ} \mathrm{C}$ for 24 - 48 hours aerobically.

Identification of the isolates from the positive cultures was done with standard microbiological techniques, which included gram stain and biochemical reactions. [9]

After confirmation of the organisms, their antibiotic sensitivity pattern was detected by Modified Kirby-Bauer Disc Diffusion method on two Mueller-Hinton Agar plates/Blood Agar plates (obtained from and interpreted based on CLSI guidelines 2015.[10]

The recorded data was analysed by frequency distribution method and the percentages were compared.

\section{Statistical Analysis}

Statistical analysis was performed using PASW 18.0 (SPSS Inc., Chicago, USA). Frequency statistics was done on the data collected and expressed in percentage.

\section{RESULTS}

A total of 280 wound swab samples were collected and processed. Of these, 252 (90\%) samples showed aerobic bacterial growth and 28 (10\%) were sterile; 228 (90.4\%) specimens yielded growth of a single organism, while the rest of the $24(9.5 \%)$ samples showed two isolates.

Among the gram-positive isolates Staphylococcus aureus (17.46\%) was predominant, while Escherichia coli (38.09\%), Pseudomonas aeruginosa (19.04\%) and Acinetobacter species $(7.9 \%)$ were most common isolates amongst gram negative rods. Some of the other isolates were Klebsiella pneumoniae, Proteus mirabilis, Citrobacter freundii and Staphylococcus epidermidis.
Figure 1 depicts the number of positive cultures in diabetics and non-diabetics. Cause of wound in Diabetic and Non-Diabetic cases is compared in Table 1. Table 2 gives the number and percentage of gram-positive, gram-negative and mixed isolates from different wound swabs in both the groups.

Figure 2 shows antibiotic susceptibility of gram negative isolates from wound infections of diabetic and non-diabetic patients. Similarly, Figure 3 gives the antibiotic susceptibility of gram-positive isolates from wound infections of diabetic and non-diabetic patients.

\begin{tabular}{|c|c|c|}
\hline Cause of Wound & Diabetic Cases & $\begin{array}{c}\text { Non-Diabetic } \\
\text { Cases }\end{array}$ \\
\hline $\begin{array}{l}\text { Surgical Site (post- } \\
\text { operative wound) }\end{array}$ & $48(17.14 \%)$ & $40(14.29 \%)$ \\
\hline Traumatic & $100(35.71 \%)$ & $92(32.86 \%)$ \\
\hline \multicolumn{3}{|c|}{ Table 1. Cause of Wound } \\
\hline
\end{tabular}

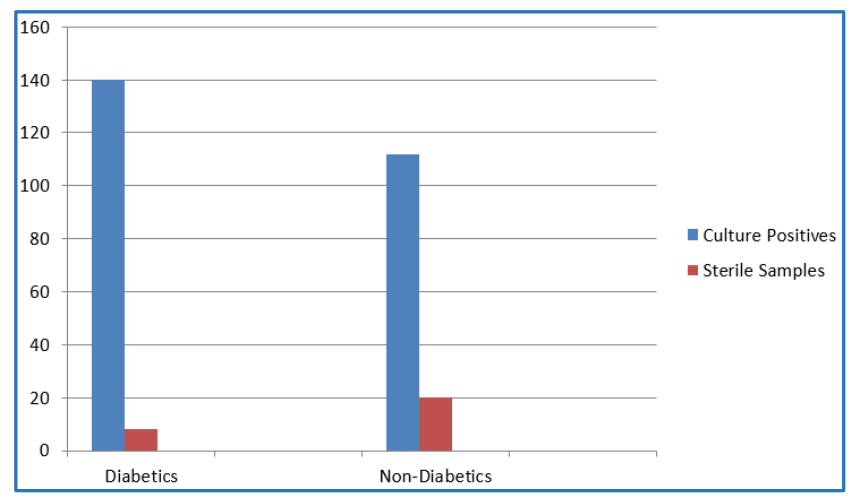

Figure 1. Frequency of Culture-Positive in Diabetics and Non-Diabetics

\begin{tabular}{|c|c|c|}
\hline Organism & Diabetic & Non-Diabetic \\
\hline \multicolumn{3}{|l|}{ Gram Positive Isolates } \\
\hline Staphylococcus aureus & $20(14.29 \%)$ & $24(21.43 \%)$ \\
\hline Staphylococcus epidermidis & $4(2.86 \%)$ & \\
\hline \multicolumn{3}{|l|}{ Gram Negative Isolates } \\
\hline Escherichia coli & $56(40 \%)$ & $40(35.71 \%)$ \\
\hline Klebsiella pneumoniae & $4(2.86 \%)$ & - \\
\hline Proteus mirabilis & $4(2.86 \%)$ & $4(3.57 \%)$ \\
\hline Pseudomonas aeruginosa & $24(17.14 \%)$ & $24(21.43 \%)$ \\
\hline Acinetobacter sps. & $4(2.86 \%)$ & $16(14.29 \%)$ \\
\hline Citrobacter freundii & $4(2.86 \%)$ & \\
\hline \multicolumn{3}{|l|}{ Mixed Isolates } \\
\hline $\begin{array}{l}\text { Citrobacter freundii + } \\
\text { Pseudomonas species }\end{array}$ & - & $4(3.57 \%)$ \\
\hline Klebsiella + Pseudomonas & $4(2.86 \%)$ & - \\
\hline $\begin{array}{c}\text { Klebsiella }+ \\
\text { Staphylococcus aureus }\end{array}$ & $4(2.86 \%)$ & - \\
\hline $\begin{array}{c}\text { Staphylococcus aureus + } \\
\text { E.coli }\end{array}$ & $4(2.86 \%)$ & - \\
\hline Klebsiella + Citrobacter & $4(2.86 \%)$ & - \\
\hline $\begin{array}{l}\text { Staphylococcus aureus + } \\
\text { Pseudomonas aeruginosa }\end{array}$ & $4(2.86 \%)$ & - \\
\hline \multicolumn{3}{|c|}{$\begin{array}{c}\text { Table 2. Distribution Pattern of Isolates } \\
\text { from Wound Swabs Under Study }\end{array}$} \\
\hline
\end{tabular}




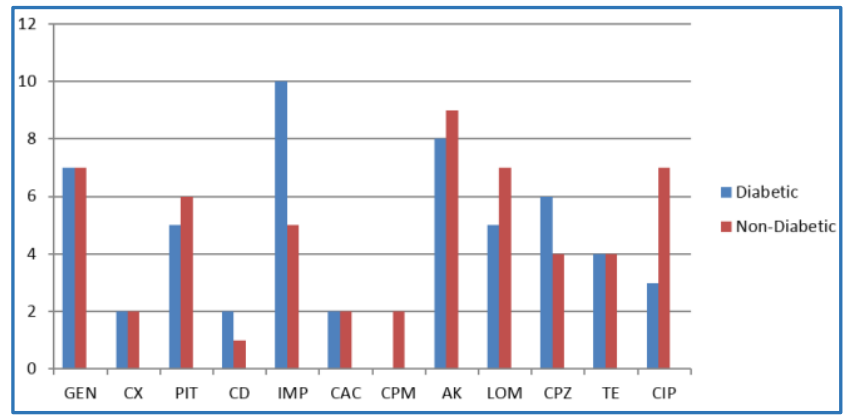

Figure 2. Antibiotic Susceptibility of Gram Negative Isolates from Wound Infections of Diabetic and NonDiabetic Patients

Gentamycin $10 \mu \mathrm{g}$ (GEN), Piperacillin + Tazobactam 100 $\mu \mathrm{g}+10 \mu \mathrm{g}$ (PIT), Imipenem $10 \mu \mathrm{g}$ (IPM), Ceftazidime + Clavulanic Acid $30 \mu \mathrm{g}+10 \mu \mathrm{g}$ (CAC), Cefepime $30 \mu \mathrm{g}$ (CPM), Amikacin $10 \mu \mathrm{g}(\mathrm{AK})$, Levofloxacin $10 \mu \mathrm{g}$ (LE), Cefoperazone $75 \mu \mathrm{g}$ (CPZ), Tetracycline $30 \mu \mathrm{g}$ (TE), Ciprofloxacin $5 \mu \mathrm{g}$ (CIP).

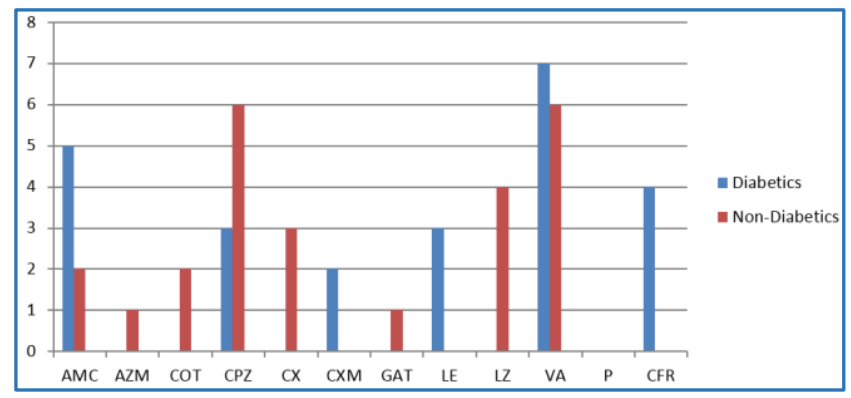

\section{Figure 3. Antibiotic Susceptibility of Gram Positive Isolates from Wound Infections of Diabetic and Non-Diabetic Patients}

Amoxyclav $10 \mu \mathrm{g}$ (AMC), Azithromycin $30 \mu \mathrm{g}$ (AZM), Cefoperazone $75 \mu \mathrm{g}(\mathrm{CPZ})$, Cotrimoxazole $1.25 \mu \mathrm{g}+23.75 \mu \mathrm{g}$ (COT), Levofloxacin $10 \mu \mathrm{g}$ (LE), Linezolid $15 \mu \mathrm{g}$ (LZ), Gatifloxacin $5 \mu \mathrm{g}$ (GAT), Vancomycin $30 \mu \mathrm{g}$ (VA) and Cefoxitin $30 \mu \mathrm{g}(\mathrm{CX})$.

\section{DISCUSSION}

$90 \%$ of the wounds in the present study were found to be infected. Incidence of wound infection was higher in diabetics $(55.56 \%)$ in comparison with non-diabetics (44.44\%). The greater frequency of infection in diabetic cases could be due to the hyperglycaemic condition, which favours immune dysfunction (e.g. Damage to neutrophilic activity, depression of antioxidant system and humoral immunity), damage to micro- and macro-vasculature and neuropathy.[11]

In most cases of wound infections, the pathogens were most likely to have originated from endogenous flora of patient's skin, mucous membrane or hollow viscera.[12] The risk of infection increases if the site is contaminated with more than $10^{5}$ organisms per gram of tissue.[13] The dose required for infection would be even lower if a foreign body is present at the site of wound.

Staphylococcus aureus is the most common gram-positive bacterium infecting wounds in diabetics and non-diabetics. This finding is consistent with previous reports.[14,15] In vitro sensitivity testing of this study showed that Vancomycin was the most effective antibiotic against Staphylococcus aureus both in diabetic (75\%) and non-diabetic (100\%) cases; $16.67 \%$ isolates of Staphylococcus aureus from non-diabetic patients were sensitive to Gatifloxacin and Azithromycin each, while those from diabetic cases showed complete resistance to these drugs; $100 \%$ isolates of Staphylococcus aureus from non-diabetic cases were sensitive to Cefoperazone, while only $25 \%$ of those from diabetic cases were sensitive to it. Staphylococcus aureus from diabetic cases were least sensitive to Levofloxacin (25\%), while those from non-diabetic cases were completely resistant. Increased drug resistance of pathogens isolated from diabetic samples may be due to formation of biofilms.[16] Prevalence of Methicillin Resistant Staphylococcus aureus was found to be $42.8 \%$, a finding consistent with other similar studies.[17]

It was observed during the course of this study that gramnegative bacteria are the most common $(71.42 \%)$ pathogens involved in wound infections, Escherichia coli being the most prevalent (44.44\%) both in diabetic and non-diabetic cases; $62.5 \%$ cases of Escherichia coli from non-diabetic patients showed sensitivity to Gentamycin, while only $25 \%$ of those from diabetic patients showed sensitivity to this drug; $42.86 \%$ of E. coli from non-diabetic cases were found to be sensitive to Amikacin, while only $18.75 \%$ of those from diabetic cases were sensitive to this drug; $37.5 \%$ isolates of Escherichia coli from non-diabetic cases showed sensitivity to Piperacillin + Tazobactam, 25\% were sensitive to Cefoperazone and $12.5 \%$ were sensitive to Tetracycline, whereas $25 \%$ isolates of E. coli from diabetic cases were sensitive to Cefoperazone, Tetracycline and Piperacillin + Tazobactam each. Difference in susceptibility to Tetracycline could be explained by lesser over-the-counter sale of this drug and lack of prescription from doctors owing to its toxicity; $37 \%$ isolates of Escherichia coli were found to be positive for ESBL.

$42.86 \%$ of Pseudomonas isolates from non-diabetic cases were sensitive to Ciprofloxacin and Amikacin each, while only $11.11 \%$ of those from diabetic cases were sensitive to Amikacin. Pseudomonas from diabetic cases were completely resistant to Ciprofloxacin. Levofloxacin was highly effective (42.86\%) against Pseudomonas from non-diabetic cases, while it was least effective $(11.11 \%)$ in diabetic cases. In most cases of infection with this organism, the integrity of a physical barrier to infection (e.g. skin, mucous membrane) is lost or an underlying immune deficiency (e.g. neutropaenia, immune suppression) is present. Thus, it has been found to be a common pathogen in cases of wound infections associated with burns cases, an observation similar to that of S Upadhaya et al.[18]

Multiple antibiotic resistance (resistance to 5 or more antibiotics) was seen more in gram negative isolates from diabetic cases, a finding similar to that of Walelign Dessie et al.[19]

\section{CONCLUSION}

Infection rates were found to be higher among diabetics in comparison with non-diabetics. Polymicrobial infection was noticed majorly $(83.33 \%)$ in diabetic cases probably due to the decreased host immunity and frequent infections in diabetes. Isolates from diabetic cases of wound infections showed greater drug resistance, which may be due to the formation of biofilms. Three important measures that help in reduction of transmission of resistant strains are hand- 
hygiene among healthcare workers, restriction of antibiotic usage and detection and isolation of patients with multi-drug resistant strains which is central to most national guidelines.

\section{ACKNOWLEDGEMENT}

We authors thank Dr. Mehnaaz Sameera Arifuddin for helping us with Statistical analysis. We also like to thank our patients without whom this study would not have been possible. The authors also take this opportunity to thank the Indian Council of Medical Research, New Delhi (ICMR STS-2014-00692) program for partly supporting this study.

\section{REFERENCES}

[1] http://www.clinimed.co.uk/WoundCare/Education/Wound-Essentials/What-is-awound-.aspx. 2013.

[2] Bandaru NR, Rao RA, Prasad VK, et al. A prospective study of postoperative wound infections in a teaching hospital of rural setup. Journal of Clinical and Diagnostic Research 2012;6(7):1266-71.

[3] http://www.2ndchance.info/diabetescatendocrinepancreas.pdf. 2014.

[4] Umasankar K, Nambikkairaj B, Backyavathy MD. A preliminary study on the isolation and identification of aerobic bacteria from diabetic foot infection and its antibiogram. International Journal of Pharmacology Research 2014;4(1):1-5.

[5] Alsaimary IEA. Bacterial wound infections in diabetic patients and their therapeutic implications. Medical Practice and Review 2010;1(2):12-5.

[6] Fernandez-Real JM, Lopez-Bermejo A, Vendrell J, et al. Burden of infection and insulin resistance in healthy middle-aged men. Diabetes Care 2006;29(5):1058-64.

[7] Pîrvănescu $H$, Bălăşoiu M, Ciurea ME, et al. Wound infections with multi-drug resistant bacteria. Chirurgia (Bucur) 2014;109(1):73-9.

[8] Ray I. General microbiological techniques. In: Standard operating procedure manual for microbiology laboratories, National Institute of Biologicals, Ministry of Health and Family Welfare, Government of India. 1995:1-28.

[9] Collee JG, Miles RS, Watt B. Tests for identification of bacteria. In: Collee JG, Fraser AG, Marmion BP, et al. eds. Mackie and McCartney practical medical microbiology. $14^{\text {th }}$ edn. New York: Churchill Livingstone 1996;7:131-49.
[10] Clinical and Laboratory Standards Institute. Performance standards for anti-microbial susceptibility testing: 24th Information Supplement. Wayne PA: 2014;34(1):M100-S24.

[11] Casqueiro J, Casqueiro J, Alves C. Infections in patients with diabetes mellitus: a review of pathogenesis. Indian J Endocrinol Metab 2012;16(Suppl 1):S27-S36.

[12] Mangram AJ, Horan TC, Pearson ML, et al. Guideline for prevention of surgical site infection, 1999. Center for Disease Control and Prevention (CDC). Hospital Infection Control Practices Advisory Committee. Am J Infect Control 1999;27(2):97-134.

[13] Krizek TJ, Robson MC. Evaluation of quantitative bacteriology in wound management. Am J Surg 1975;130(5):579-84.

[14] Oncul O, Ulkur E, Acar A, et al. Prospective analysis of nosocomial infections in a burn care unit, Turkey. Indian J Med Res 2009;130(6):758-64.

[15] Slater RA, Lazarovitch T, Boldur I, et al. Swab cultures accurately identify bacterial pathogens in diabetic foot wounds not involving bone. Diabet Med 2004;21(7):705-9.

[16] Joseph WS. Treatment of lower extremity infections in diabetics. Drugs 1991;42(6):984-96.

[17] Tyagi A, Kapil A, Singh P. Incidence of Methicillin Resistance Staphylococcus aureus (MRSA) in pus samples at a tertiary care hospital, AIIMS, New Delhi. JIACM 2008;9(1):33-5.

[18] Upadhaya S, Shenoy R, Shetty V, et al. Multi-Drug resistant pseudomonas aeruginosa isolated from intensive care burn unit. International Journal of Biomedical Research 2014;5(4):271-3. http://dx.doi.org/10.7439/ijbr.v5i4.584.

[19] Dessie W, Mulugeta G, Fentaw S, et al. Patttern of bacterial pathogens and their susceptibility isolated from surgical site infections at selected referral hospitals, Addis Ababa, Ethiopia. Article ID 2418902, International Journal of Microbiology 2016;2016: p. 8. http://dx.doi.org/10.1155/2016/2418902. 